\title{
INTRAMOLECULAR RESPIRATION OF TOMATO FRUITS 1
}

\author{
Felix G. Gustafson
}

(Received for publication June 5, 1930)

These experiments on intramolecular respiration have been conducted as a part of a general study of the development of tomato fruits. Nitrogen and in two experiments hydrogen have been used to replace air. These gases were first passed through a wash bottle containing $\mathrm{NaOH}$ which absorbed the $\mathrm{CO}_{2}$ and then through three bottles of chromous chlorid which absorbed any oxygen that was in the gas. The $\mathrm{CO}_{2}$ - and $\mathrm{O}_{2}$-free gas was then passed through the respiration chamber by the pressure in the tank and reduction of the pressure in the system by suction. As it came from the chromous chlorid the gas was frequently tested for oxygen by passing it over phosphorus, always with negative results. The respiration chamber was always kept at atmospheric pressure and was immersed in a constant temperature bath held at $25^{\circ} \mathrm{C}$. A control in air otherwise similarly treated was run simultaneously. The fruits were usually picked during the afternoon and put into the chamber through which air was drawn over-night in order to establish an equilibrium, before any collection for analysis was made.

The $\mathrm{CO}_{2}$ was collected in $0.1 \mathrm{M} \mathrm{Ba}(\mathrm{OH})_{2}$ contained in modified Pettenkofer tubes, and titrated with o.I $M$ oxalic acid. Further detail may be obtained from a previous paper (5). ${ }^{2}$ In the present experiments the Pettenkofer tubes had a diameter of only $9 \mathrm{~mm}$. in the main portion, with both ends enlarged somewhat, to facilitate the insertion of stoppers. The use of tubes with a small diameter made it possible to utilize a volume of only sixty cubic centimeters of $\mathrm{Ba}(\mathrm{OH})_{2}$ and yet the gas passed through a column of liquid long enough to absorb the $\mathrm{CO}_{2}$ completely. With such a small volume of liquid the time of the individual collections could be shortened to one hour in some instances. In all but one experiment the length of time for collection of each sample was from one to three hours. Such short periods enabled one to follow more closely the changes in the rate of $\mathrm{CO}_{2}$ production. In the early experiments three hour periods were used almost exclusively, but in the later experiments several fruits were used and the time could be shortened to one hour when the gas production was at its maximum.

After some preliminary trials an experiment with a ripe fruit weighing

${ }^{1}$ Paper from the Department of Botany of the University of Michigan, No. 34I.

${ }^{2}$ No reference has been made here to the rather extensive literature on anaerobic respiration of flowering plants, since previous experiments have been so very different from the ones here discussed that it has seemed unnecessary. 
$78.9 \mathrm{~g}$. was started in the afternoon and air drawn through the apparatus without any collection of gas until the next morning. This experiment is the only one conducted iiı which there was no control in air. The collection in air was made for six hours before nitrogen was introduced. As shown in text figure $\mathrm{I}^{3}$ there was an immediate rise of $\mathrm{CO}_{2}$ production when nitrogen

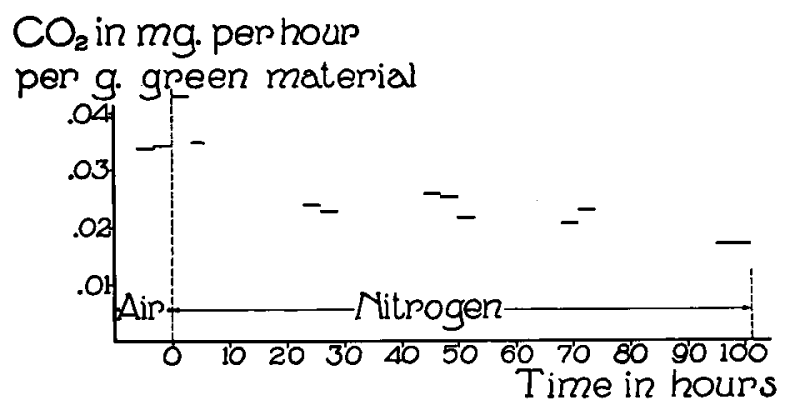

Text FIg. I. Respiration of a red-ripe tomato fruit. In this as well as in all other figures the length of the lines denotes the duration of a collection. Sometimes two collections may have the same value and the two together will be represented by a line double in length, as the last two collections in this experiment. At the zero point air was replaced by nitrogen.

was introduced, amounting to 28 percent, but during the second period of collection the $\mathrm{CO}_{2}$ production was back to the original level. During the night nitrogen was run through the apparatus at a rate similar to that during the daytime when collections were made; if, as it sometimes happened in the early experiments, the gas flow had slowed down somewhat during the night, no collections were made for several hours after the flow had been corrected in order to wash out thoroughly any $\mathrm{CO}_{2}$ that might have accumulated in the container or in the tissue. In this experiment the gas flow was less in the morning than during the preceding day and four hours were allowed to elapse before any collection was made. During this time the gas flow was the same as the preceding day. The rate of gas flow was determined by the distance between bubbles in the Pettenkofer tubes. The size of the bubbles was usually the same. This method is not very exact, but it was noted that if the gas flow thus measured was nearly the same, there was no difference in the amount of $\mathrm{CO}_{2}$ collected. By referring again to the graph in text figure $\mathrm{I}$ it will be noted that 24 hours after the nitrogen was introduced the $\mathrm{CO}_{2}$ production was $7 \mathrm{I}$ percent of that at the beginning. The experiment was continued for I02 hours in nitrogen. During this time there was a gradual decrease in $\mathrm{CO}_{2}$ production, which fell to 50 percent

${ }^{3}$ In all of these experiments the results for the experimental fruits in nitrogen are represented by either solid or interrupted lines, one line for each collection and the length representing the duration. The control is represented by circles, and each circle is the average of the several collections made each day. For the sake of simplicity the experiment number will be the same as the number of the figure representing it. 
at the end. As will be seen from other graphs in which ripe fruits were also used the control shows a decrease in production of $\mathrm{CO}_{2}$ during an experiment. During the first 24 hours in nitrogen there is then a decrease of 29 percent in the $\mathrm{CO}_{2}$ production, while during the remaining 78 hours there is a decrease of only $2 \mathrm{I}$ percent. In the same length of time a control fruit would have shown nearly the same decrease.

After the experiment on the ripe fruit others were conducted in the same manner in which fruits of various degrees of ripeness and green fruits growing at various rates were used. Of these only three experiments with their controls need to be mentioned, because the others conform to type.

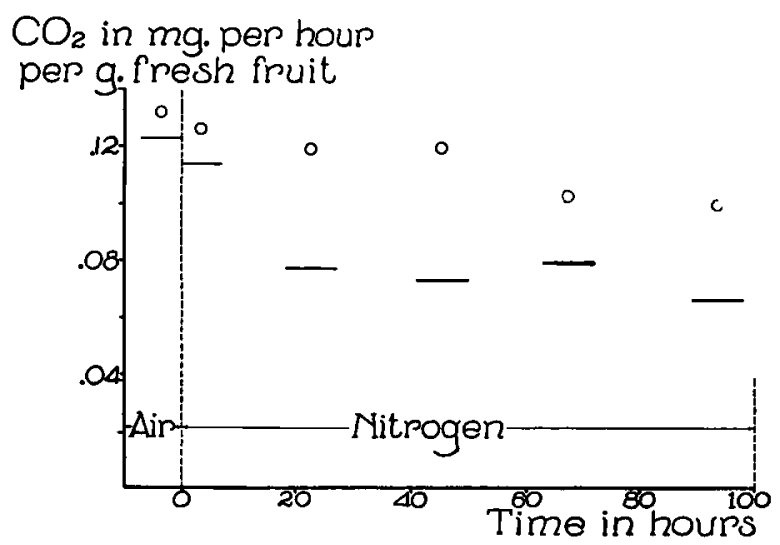

TEXT FIG. 2. Respiration of a green fruit, growth rate $5^{\circ}$ percent per day. The circles represent the control and in all experiments except this one each circle is the average of the several collections for the day.

Text figure 2 illustrates the respiration of a green fruit and its control. The fruit weighed only $4.2 \mathrm{~g}$. and had a diameter of $2.1 \mathrm{I} \mathrm{cm}$., and had had a growth rate of 50 percent per day. The control weighed $4.56 \mathrm{~g}$., was 2.08 $\mathrm{cm}$. in diameter, and had been increasing at the rate of 45 percent per day. Due to the small size of the fruits the collection period had to be very long, seven hours the first day and nine hours the following days. When nitrogen was introduced there was no apparent increase in $\mathrm{CO}_{2}$. Whether there was an initial increase which was followed by a greater decrease producing an average lower than at the beginning, or whether there was a slow decrease from the beginning cannot be stated. From subsequent experiments in which several fruits were used and the periods of collection were short it would seem that there is an initial rise followed by a drop, so that the average for seven hours would be less than normal. A day after the nitrogen was introduced the respiration had decreased to 63 percent of the original, while the control was 92 percent of its original value. During the next two days the rate of $\mathrm{CO}_{2}$ production remained nearly constant in the experimental fruit, but on the fourth day there was a considerable decrease and at the end of 
95 hours in nitrogen the respiration was 54 percent of the original, whereas in the control it was still 74 percent of its original rate. The gradual decrease in the $\mathrm{CO}_{2}$ production of the control is very typical. There was hardly ever a large decrease during any one day, but at the end of the experiment it too had dropped considerably below the initial rate. It is to be noted that these green fruits produced more than three times as much $\mathrm{CO}_{2}$ as the ripe fruits represented in text figure $\mathbf{I}$.

Several experiments were carried out in which faintly pink or yellow fruits were used but only two of them are presented in text figure 3. The

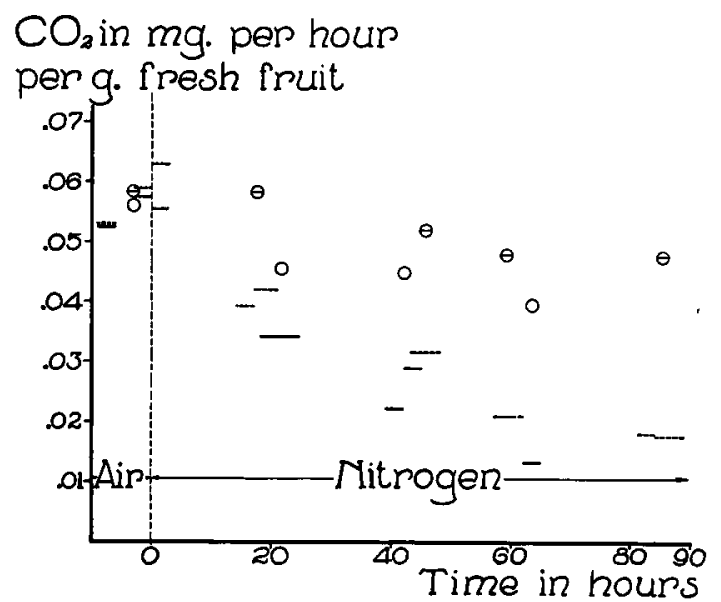

TEXT FIG. 3. This figure illustrates two experiments with their controls. The fruits were pink. The dotted lines and the circles with a line through them constitute one experiment and the solid lines and circles the other experiment.

point of note in these experiments is that the $\mathrm{CO}_{2}$ production of the fruits in the nitrogen decreased rapidly from the first day. At the end of 65 hours the $\mathrm{CO}_{2}$ production of one was only 24 percent of its initial output, while its control was still 73 percent. The other experiment produced 32 percent after having been 85 hours in nitrogen and its control 78 percent. These pink fruits behaved normally when in air, but very differently from the others when in nitrogen. They never deviated from this performance.

To find out whether the leaves reacted as the fruits did, one experiment was conducted with them (text fig. 4). The circles with the lines through them represent the leaves in nitrogen. The leaves did not hold up even as long as the pink fruits. After 50 hours in nitrogen the leaves produced only 3 percent as much $\mathrm{CO}_{2}$ as they did at the beginning of the experiment; the leaves in air respired 64 percent as much as at the beginning.

These experiments, which are well illustrated by the four given here, all show that the production of $\mathrm{CO}_{2}$ is well sustained in green or ripe fruits in the absence of oxygen but this is not true of the leaves or the pink fruits. 
The fact that in absence of oxygen tomato fruits produced a considerable amount of $\mathrm{CO}_{2}$ suggested the importance of determining what would happen if air was again introduced. Several experiments were performed in which air was reintroduced after the fruits had been some time in nitrogen and of these, two are chosen as typical.

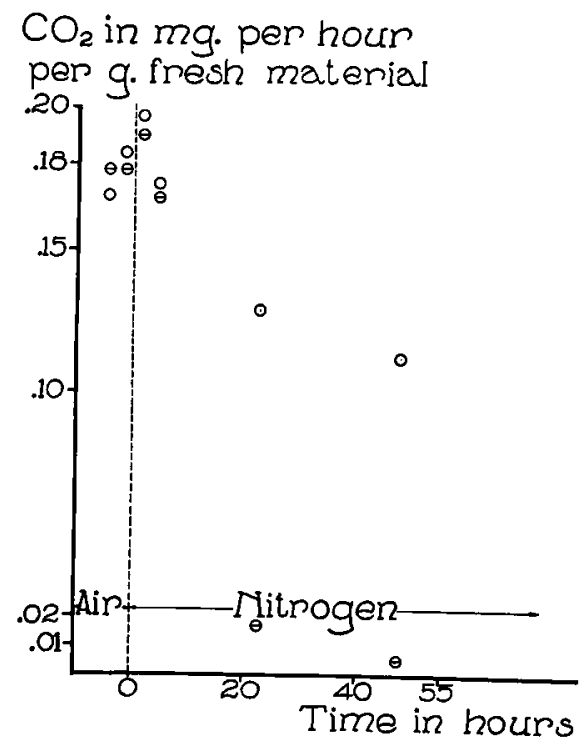

TEXT FIG. 4. An experiment with tomato leaves. The circles with the lines denote the readings of the leaves deprived of air.

Text figure 5 represents an experiment in which were used two ripe fruits with a total weight of $15 \mathrm{I} .5 \mathrm{~g}$. and diameters of 5.28 and $5.72 \mathrm{~cm}$. Two slightly larger fruits were used for the control. The three readings taken before the nitrogen was introduced were very irregular, but after that the

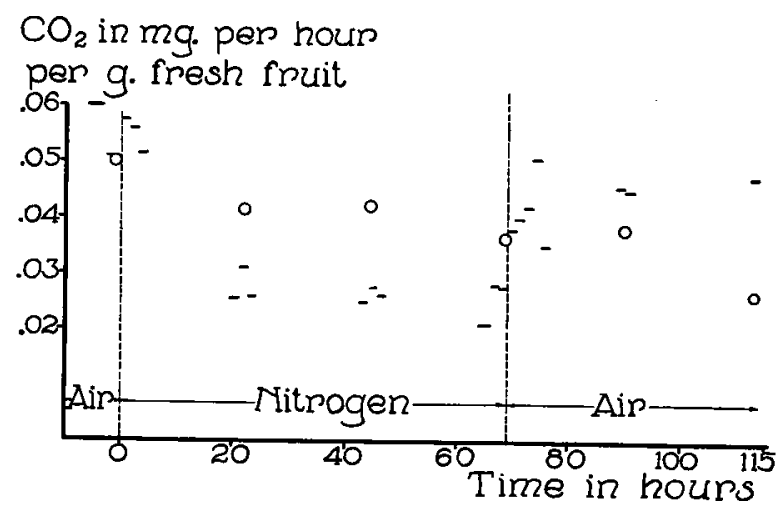

TeXT FIg. 5. Respiration of a red-ripe fruit and its control. After 69 hours in nitrogen air was reintroduced. 
$\mathrm{CO}_{2}$ production was quite uniform. The fruits were deprived of air for 69 hours and at the end of this period the $\mathrm{CO}_{2}$ production had decreased to 49 percent of the initial. As soon as air was reintroduced there was an immediate increase in $\mathrm{CO}_{2}$ output and within six hours it had reached Io2 percent of the original or had increased 104 percent over what it was in nitrogen. This rate of respiration continued during two days, when the experiment was discontinued.

The second experiment of this group was one in which two pink fruits were used. Their diameters were 5.16 and $5.92 \mathrm{~cm}$. and their combined weights $150.5 \mathrm{~g}$. The control also had two fruits, slightly smaller. Text

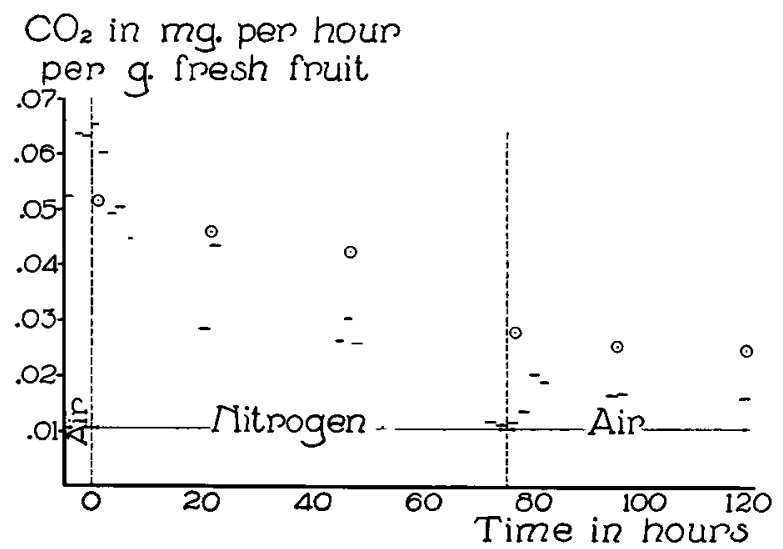

Text Fig. 6. Respiration of a slightly pink fruit. Air reintroduced after 75 hours in nitrogen.

figure 6 illustrates this experiment. As usual with the pink fruits the respiration fell rapidly and after 75 hours in nitrogen the $\mathrm{CO}_{2}$ output was only I9 percent of the initial. When air was reintroduced there was here also an increase in respiration, to 35 percent that of the initial or 80 percent over the rate in nitrogen before the air was introduced. During the two following days the rate of respiration remained nearly stationary. At the end of the experiment, I20 hours after the nitrogen was introduced, the control respired 49 percent of the original and the nitrogen treated fruits 27 percent.

Both of these examples show that when air is reintroduced there is an increase in respiration. This increase was sometimes, though not always, to a level considerably above the original.

Another group of experiments was initiated in which nitrogen was introduced a second time and in two experiments the air was introduced after the second nitrogen period. Three experiments from this group will be given, not because they are so very different in response, but since they represent fruits in very different stages of development.

The first of these was concerned with eight green fruits having an average diameter of $2.15 \mathrm{~cm}$., a combined weight of $35 . \mathrm{I} \mathrm{g}$. and a growth of 
I3 percent per day (text fig. 7). The control consisted of seven fruits of about the same size, also showing a growth of 13 percent per day. When the nitrogen was introduced there was a very decided increase in $\mathrm{CO}_{2}$ production during the second period, which was followed by two periods of very much lower production. After a period of 50 hours in nitrogen air was introduced and there was an immediate rise in respiration which continued

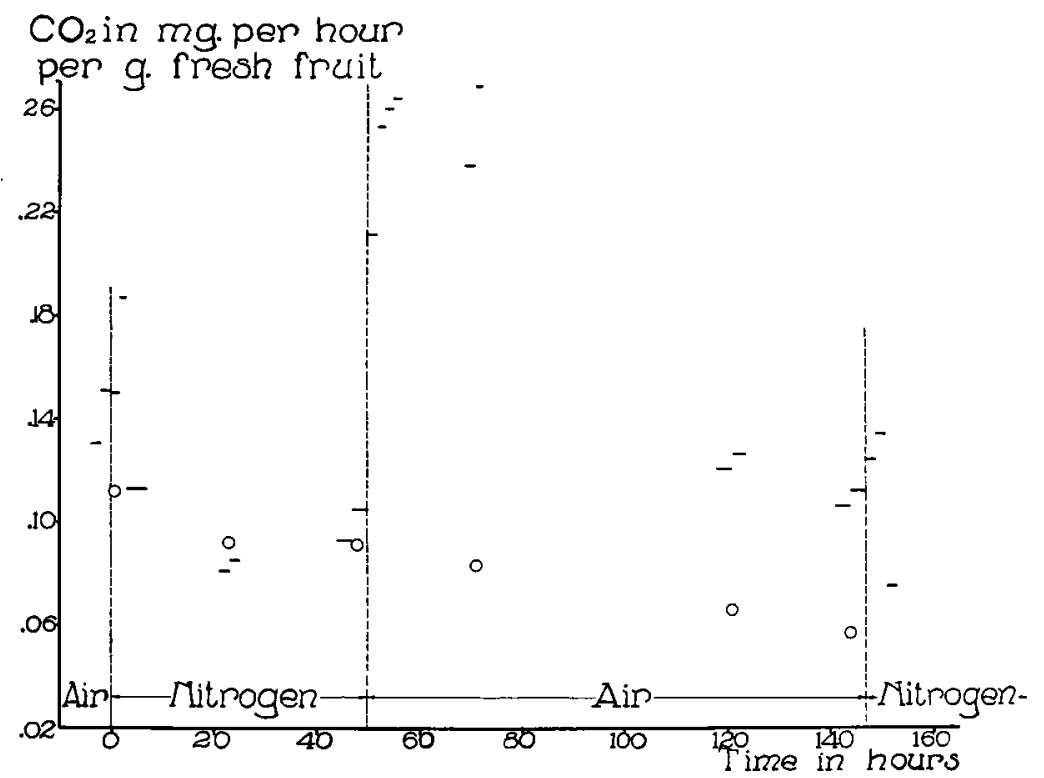

TEXT FIg. 7. Respiration of eight green fruits, average diameter $2.15 \mathrm{~cm}$., growth I 3 percent per day, and their control. Air was reintroduced after 50 hours in nitrogen, and after 97 hours in air nitrogen was introduced a second time.

for the next three periods until the rate of $\mathrm{CO}_{2}$ production was $\mathrm{I} 89$ percent of the original or an actual increase of 166 percent over the rate in nitrogen just before air was introduced. The average of two determinations made the next day was a little lower. The experiment was continued in air over Sunday and by Monday a considerable drop had occurred but the rate was still very much above that of the control. After 97 hours in air, nitrogen was introduced a second time and this time there was also a rise in respiration which lasted for four hours; but during the third period there was a very definite drop, to considerably below the rate in air immediately preceding the second nitrogen introduction. In this experiment, which lasted I 53 hours after the nitrogen was first introduced and in which the fruits were, all told, 56 hours in the nitrogen, the $\mathrm{CO}_{2}$ production at the end was greater than in the control which had been in the air during the whole period. The respiration of the control had dropped to 5I percent when the experiment was ended. 
In a second similar experiment (text fig. 8) one fruit, yellow-orange with green near the stem, weighing $94.86 \mathrm{~g}$. was used. The control had the same color and weighed $85.58 \mathrm{~g}$. These fruits were 42 hours in the respiration chamber with air drawn through before any gas was collected. At neither time of nitrogen introduction was there a rise in respiration. It

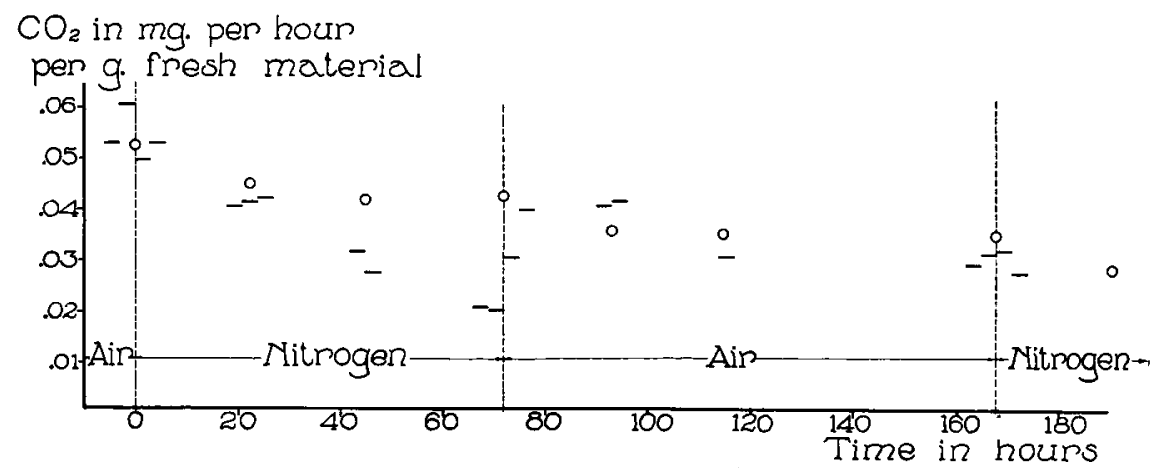

Text FIG. 8. Respiration of a yellow-orange-green fruit, and control.

will be noted that in nitrogen the respiration decreased quite rapidly but not so much as in experiments with fruits that were pink or slightly yellow, yet more than with fruits that were orange or red. On the introduction of air there was a gradual rise to the 74 percent level and this was maintained during the following day. This was an increase of 108 percent over the rate in nitrogen, when air was again admitted to the respiration chamber.

The third experiment (text fig. 9) of this group was rather long. It

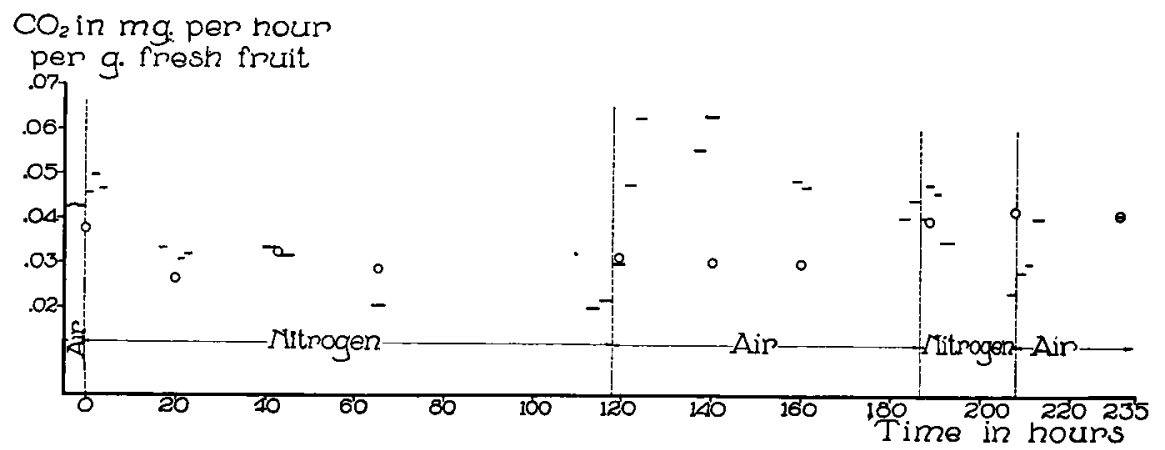

Text FIg. 9. Respiration of two green fruits, growth I.7 percent per day. In this experiment the experimental fruits were in nitrogen and air alternately for 232 hours. The control shows an increase and this is interpreted as being due to ripening. At the beginning of the experiment these fruits were green, while at the end they were yellow-orange.

lasted II days or $\mathbf{2 3 5}$ hours from the time nitrogen was first introduced through the last collection when the fruits were in air. Two green fruits were used with a total weight of $120 \mathrm{~g}$. and a daily growth increment of $\mathrm{I.7}$ 
percent. The control also consisted of two green fruits weighing I30 g. with a growth increment of 1.7 percent. When air was first displaced by nitrogen there was a rise in $\mathrm{CO}_{2}$ production, which was not very great. During the II 8 hours in nitrogen there was a gradual decline in $\mathrm{CO}_{2}$ production from 76 percent of the original, 20 hours after the start, to 48 percent at the end. When the nitrogen was replaced by air after this long period of intramolecular respiration the $\mathrm{CO}_{2}$ production rose in seven hours to $\mathrm{I} 47$ percent of the original or an increase above the respiration in nitrogen of 206 percent. This rate continued the next day, but fell on the third day, reaching 99 percent on the fourth. When nitrogen was introduced a second time there was a rise. followed by a very sharp decline to 54 percent. A second replacement of nitrogen by air brought production of $\mathrm{CO}_{2}$ up to I Io percent, at which level it remained during the next day. This experiment is interesting because of the long sustained intramolecular respiration and the very large increase noted both times when the air was reintroduced. The experiment is also of interest because of the behavior of the control, which reached its lowest respiration level (67 percent) during the second day of measurement, after which there was a slight increase that was maintained for several days until on the ninth day there was a marked increase which continued the next day. The results fall in line with those presented in a previous paper (4) indicating that tomato fruits reach their minimum rate of respiration at about the time they begin to change color, after which time there is an increase up to the time they become orange-red. At the end of this experiment the fruit in the control was yellow-orange, while at the commencement it had been green.

Before discussing the experiments it may be appropriate to summarize the results briefly. In most experiments there was an increase in $\mathrm{CO}_{2}$ output when nitrogen replaced air either the first or second time. This increase was quickly followed by a very large decrease, after which there was only a very gradual fall, except in pink or yellow fruits, in which the decrease was quite large during the whole of the nitrogen period. The replacement of nitrogen by air always brought about an increase in $\mathrm{CO}_{2}$ output, varying from about 80 percent to over 200 percent above that in nitrogen just before air was reintroduced. In some experiments much more $\mathrm{CO}_{2}$ was given off in air than during the periods before nitrogen was introduced, whereas in others there was less, but in only one experiment was there less than in the control at that time. Sometimes several periods were required before the maximum $\mathrm{CO}_{2}$ output had been reached, but in all instances the respiration during the first period in air was higher than the last period in nitrogen. After air was reintroduced the $\mathrm{CO}_{2}$ production remained high for the remainder of the aërobic respiration.

A discussion of these experiments can be divided into two sections, one dealing with the intramolecular or nitrogen phase and the other with the aërobic or oxygen phase. 
In most of the experiments and in all in which the time of collection was short, there was an initial rise in $\mathrm{CO}_{2}$ output when nitrogen replaced the air. How is this increase to be explained? In the absence of oxygen, theoretically only one-third of the carbon is used in $\mathrm{CO}_{2}$ formation while in air all of the carbon goes into the formation of $\mathrm{CO}_{2}$, so that if the production of $\mathrm{CO}_{2}$ were the same in both, three times as much carbon material would be used in intramolecular respiration as in aërobic respiration. In most experiments, however, there is an increase in $\mathrm{CO}_{2}$ production when $\mathrm{O}_{2}$ is excluded.

One explanation that comes to mind is that this increase is only apparent, and results only from an outpouring of $\mathrm{CO}_{2}$ already in the fruit in the intercellular spaces, due to the difference in diffusion of oxygen and nitrogen. If nitrogen diffused more rapidly than the oxygen the total pressure in the interior would increase and some $\mathrm{CO}_{2}$ might be driven out. However, their diffusion rate is practically the same. The coefficient of diffusion of nitrogen into pure water at $19^{\circ} \mathrm{C}$. is $1.9 \times 10^{5} \mathrm{~cm} .{ }^{2} / \mathrm{sec}$., and that of oxygen at $18^{\circ}$ C. is $1.9 \times 10^{5} \mathrm{~cm} .{ }^{2} / \mathrm{sec}$. (6). Of course there might be some difference in their ability to penetrate the membranes in the fruit, but apparently in the case of nitrogen and oxygen there is no such difference. Hydrogen, on the other hand, does seem to bring about an outpouring of $\mathrm{CO}_{2}$. In two experiments to be discussed later hydrogen was used to displace air and here the initial rise of $\mathrm{CO}_{2}$ output when air was replaced was greater than when nitrogen was used as a substitute. This was probably due to the more rapid diffusion of hydrogen, which increased the gas pressure within the fruit. Flow of the mixture of gases within the fruit to the outside, through the stem scar, would take place until equilibrium was attained. This view is further strengthened by the fact that when hydrogen was replaced by air the increase was less than when nitrogen was used. Here the hydrogen diffused out more rapidly than air came in and some $\mathrm{CO}_{2}$ remained in the intercellular spaces because of a reduction in total pressure. Hydrogen has, of course, a much greater rate of diffusion than nitrogen, and it seems that the increase in $\mathrm{CO}_{2}$ output on replacement of air by nitrogen is not due to nitrogen driving the $\mathrm{CO}_{2}$ out of the system, but rather to an actual increase in $\mathrm{CO}_{2}$ production.

How is this increase to be explained? A schema proposed by Blackman (I) may supply an explanation, as follows:

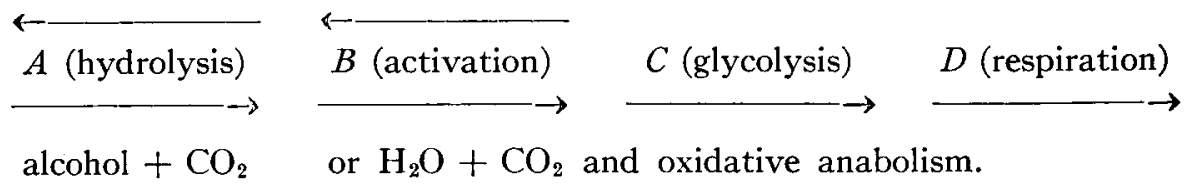

$(A)$ he considers as any complex carbohydrates which are hydrolysed to any number of sugars $(B)$; these sugars are changed to the more unstable ring compounds $(C)$ in activation; the active sugars are changed to the three 
carbon atom compounds $(D)$ and this is called glycolysis; the compounds $(D)$ are then used in respiration, forming $\mathrm{CO}_{2}$ and $\mathrm{H}_{2} \mathrm{O}$ in air and $\mathrm{CO}_{2}$ and alcohol in absence of air. Blackman assumes that during aërobic respiration a large part of the intermediate products $(D)$ are not used in respiration but go back into the system. When air is excluded, however, this process stops, leaving more material to be used in respiration. This intermediate material accounts for the increase in $\mathrm{CO}_{2}$ production on introduction of nitrogen and as soon as this excess is used up there is a drop to a lower level characteristic of intramolecular respiration.

If all of the product $D$ is used in respiration in absence of air why does the rate of $\mathrm{CO}_{2}$ production decrease after the first few hours? Blackman assumes that the production of $D$ is not influenced by oxygen, but that the formation of either $B$ or $C$ or possibly both is influenced by the oxygen pressure and that in absence of oxygen they decrease, and even though all of $D$ is used in respiration, the total is less than in air. This explanation is not satisfactory, but the writer has none of his own to offer. When hydrogen replaces air part of the increase is only apparent and is due to a more rapid penetration of hydrogen, which then drives some $\mathrm{CO}_{2}$ out of the system because of the increased pressure in the tissue, but here also there is an actual increase in respiration as explained above.

With the exception of those experiments in which either pale yellow or pink fruits were used, the rate of $\mathrm{CO}_{2}$ production after the first 24 hours in nitrogen decreased only slightly, not any more than that of similar fruits in air. This would seem to show that respiration in nitrogen is a well balanced or regulated process which merely produces less $\mathrm{CO}_{2}$ than when the fruits are in air. It is on a lower $\mathrm{CO}_{2}$-producing level than in air.

When air replaced nitrogen there was always an increase in $\mathrm{CO}_{2}$ production. In some experiments this increase amounted to over 200 percent, although in others it was less than Ioo percent. If the introduction of nitrogen does not bring about an outpouring of $\mathrm{CO}_{2}$ from the tissue, neither can its replacement be accredited with this, and an explanation for the increase must be looked for in another direction.

It was first suggested by Pfeffer and later by other investigators that in the absence of air substances are produced which are rapidly consumed in the air to produce $\mathrm{CO}_{2}$. These are not the intermediate compounds $(D)$ of Blackman, but probably a decomposition product of them. In intramolecular respiration only one-third of the carbon appears as $\mathrm{CO}_{2}$. The other two-thirds are supposed to be used in the formation of alcohol, but not much alcohol is found in higher plants when they have been in nitrogen. So far in these experiments no careful attempts have been made to detect alcohol in tomatoes. However, in the crude qualitative tests made there has been no definite detection of alcohol. If alcohol is not formed other products may be, which are later used in aërobic respiration. In many plants, particularly in succulents, quantities of organic acids are found. 
Any number of compounds might be formed in the absence of air which are easily oxidized in the presence of oxygen.

Meyerhof (7) has a somewhat different idea about the increase in respiration after a period of intramolecular respiration. It has been shown that the lactic acid formed in the contraction of muscles disappears during the recovery or aërobic phase of muscular activity. He thinks that the lactate ion stimulates aërobic respiration, which utilizes not the lactic acid but the glycogen, and that part of the energy so obtained is used to convert the lactic acid formed during the intramolecular phase of muscular activity back to glycogen. The stimulation of aerobic respiration of a muscle by the lactate ion can also be demonstrated by placing an uninjured muscle in a lactate-containing salt solution, when the respiration will be increased two to three times.

Here are two different views attempting to account for the increase in respiration which is noticed when intramolecularly respiring organisms are brought back into air. Both hold that a compound or compounds are formed during the intramoledular period which are responsible for this increase, but according to one these substances are actually used in producing the increased amount of $\mathrm{CO}_{2}$, while according to the other they act as a stimulant.

If something is formed in these tomato experiments during the nitrogen period which is later used in aërobic respiration, shorter periods of respiration in nitrogen should produce less of this material than longer periods, and respiration in air should increase less, or at least the period of increase should be shorter, than when the nitrogen periods are long, unless so much of this hypothetical intermediate substance is formed as to become poisonous.

To investigate this idea several experiments were conducted in which

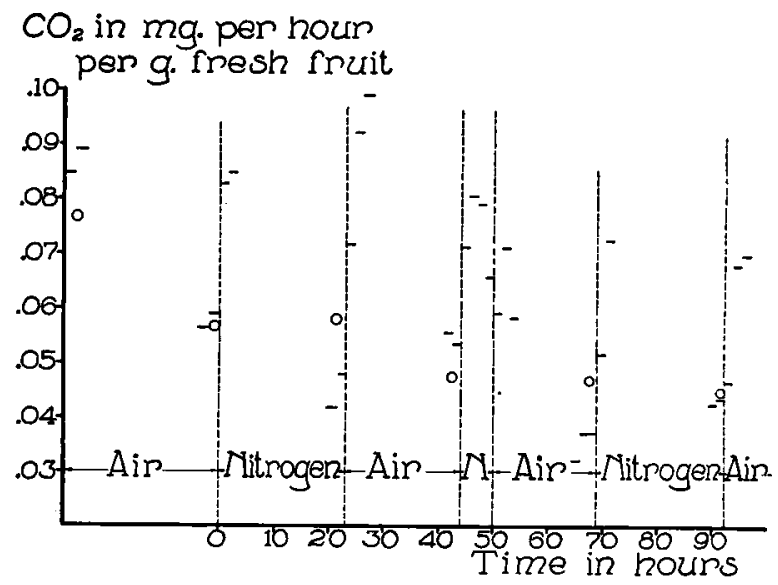

TeXT FIG. Io. Respiration of six green fruits, growth 6.3 percent per day. This experiment was conducted to determine the effect of the length of the nitrogen period on the amount of $\mathrm{CO}_{2}$ produced when air was again admitted. It shows that following a short nitrogen period the $\mathrm{CO}_{2}$ is much less than that following a longer nitrogen period. 
the length of the nitrogen periods was varied. One of these is given here. In experiment Io figured in text figure Io, six green fruits having a total weight of $I 18.25 \mathrm{~g}$. with an average diameter of $3.4 \mathrm{~cm}$. and a grow th rate of 6.3 percent per day were used. The control fruits were slightly smaller and had a growth rate of 5.84 percent. This experiment was started in the evening and the first determinations made the next morning. It was continued in air for this day and part of the next. It will be noticed in the graph that both the experimental fruits and the controls decreased much in their respiratory rate during these first 24 hours. When nitrogen was introduced there was a greater increase in $\mathrm{CO}_{2}$ than usual. Next day the $\mathrm{CO}_{2}$ production was down to 77 percent of what it was at the time nitrogen was introduced. This result is typical of fruits growing at the rate these were. The increase on nitrogen replacement was about as great as could be expected, but the fall to 94 percent in 20 hours was greater than usual. Next, a nitrogen period of only six hours was used and this time the rise in air was very slight and was followed by a decrease within a few hours and the next morning it was down to 64 percent. A third period of nitrogen produced a large increase. This nitrogen period lasted 23 hours and on the introduction of air there was an increase in $\mathrm{CO}_{2}$ production of 60.5 percent, showing that the fruits were by no means exhausted. The only time the respiratory rate of the experimental fruits went below the control, after the first nitrogen period, was when they were in air following the brief nitrogen period.

This experiment makes it very clear that when tomato fruits are deprived of nitrogen some substance is formed which later is either used in respiration or stimulates respiration in air. It is of course impossible to state which is the true state of affairs, but it will be considered that the material is actually used in the production of $\mathrm{CO}_{2}$ and water. Even though the 23 hour period was followed by a normal rise, in air, yet it becomes very evident by referring to previous graphs that not as much $\mathrm{CO}_{2}$ was produced as would have been in a longer period, and the 6 hour period was so short that very little material was formed. If comparisons are made between different experiments it will be evident that the more actively growing fruits produce much more of this unknown substance during intramolecular respiration than do fruits that have ceased growing and are ripening.

To check the effect of nitrogen two experiments were conducted in which hydrogen replaced air. Only one of these will be cited. It is designated as experiment II, illustrated by text figure II. In this experiment eight green fruits were used, having a total weight of $130.5 \mathrm{~g}$. with an average diameter of $3.37 \mathrm{~cm}$. and a growth increment of 6 percent per day. The control had 7 green fruits weighing II5.75 g. and growing at the rate of 6.5 percent per day. The experiment lasted $\mathrm{I} 3$ days from the time the fruits were put in to the apparatus until the last collection was made. The first Ioo hours after air was replaced were an exact duplicate of experiment to except that 
$\mathrm{CO}_{2}$ in ma. per,

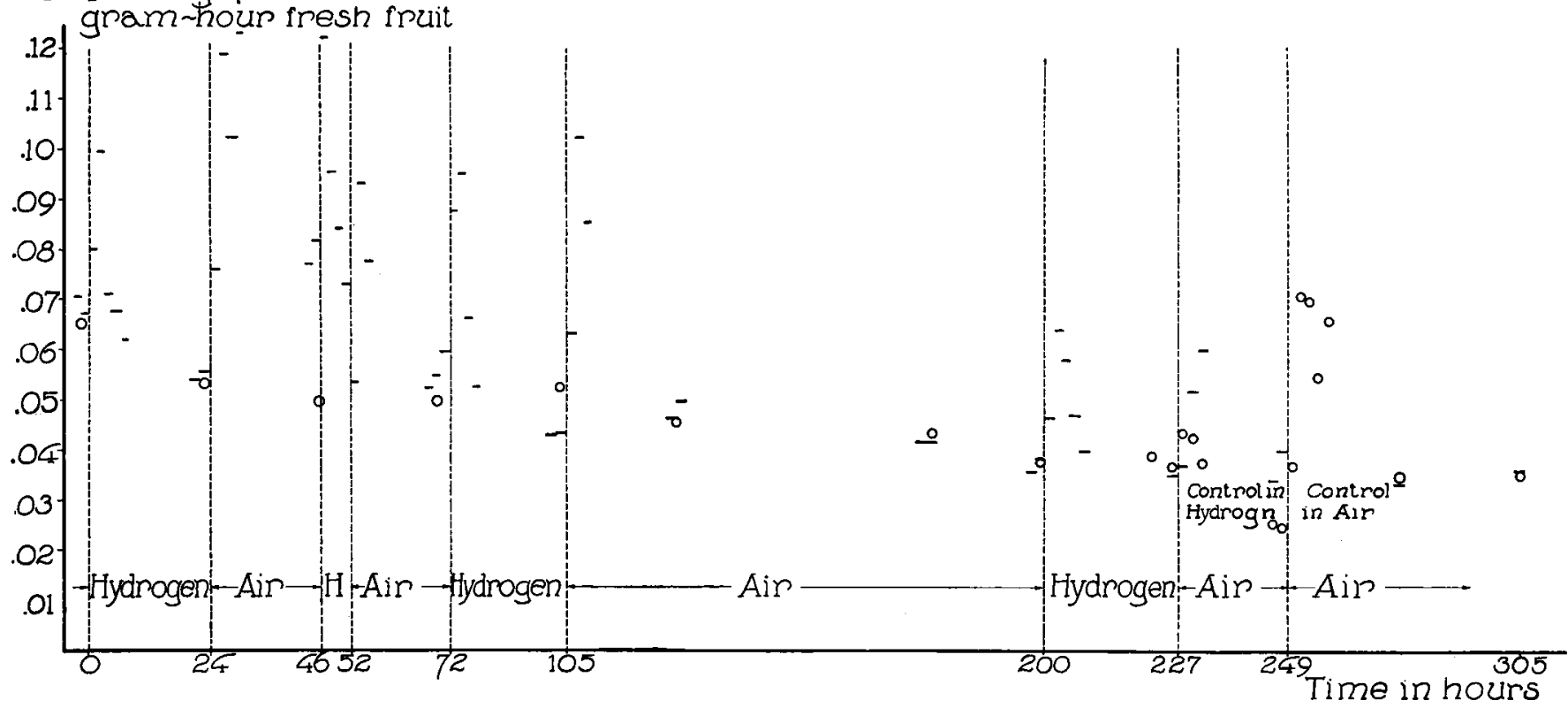

TeXt FIG, I I. Respiration of eight green fruits, growth 6.o percent per day. In this experiment air was replaced by hydrogen instead of nitrogen as in previous experiments. Aside from this fact, the experiment is a duplicate of experiment Io, after the introduction of hydrogen for the first Ioo hours. It will be noted that when hydrogen replaces air the rise in $\mathrm{CO}_{2}$ production is slightly higher than when nitrogen replaces air in fig. Io (see text for explanation). In the latter part of this experiment the control had its air replaced by hydrogen for a 22 hour period. 
hydrogen replaced nitrogen. Experiment II, however, was continued for 200 hours longer.

As mentioned in another place the rise in $\mathrm{CO}_{2}$ output when air is replaced by hydrogen is a little greater than when nitrogen replaces air, a result which is attributed to the more rapid diffusion of hydrogen. Aside from that fact there is no essential difference between experiments Io and II. When the hydrogen period was only six hours the rise in $\mathrm{CO}_{2}$ was also less in this experiment than when the period was longer. A feature of this experiment is the replacement of air by hydrogen in the control near the end. When hydrogen was introduced at the 20oth hour the rise in $\mathrm{CO}_{2}$ output was not so great as in earlier replacements and an attempt was made to determine whether this was due to injury produced by the lack of air for several periods or whether it was due to natural causes operating in fruits that had been picked for some time. For this purpose hydrogen was introduced into the control respiration chamber at the 227th hour. The rise in $\mathrm{CO}_{2}$ was even less in the control than in the experimental fruits, so the lower production was not due to any injury. Air was again admitted to the control after 22 hours in hydrogen and the rise in $\mathrm{CO}_{2}$ elimination was a little higher than in the experimental fruits 22 hours before. This experiment also shows very conclusively that the increased $\mathrm{CO}_{2}$ production is not due to injury, because as soon as the effect of the intramolecular respiration was over the aërobic respiration of the experimental fruits came down to the level of the control as shown at the 125-, 175-, 200-, 280-, and 305-hour periods, when it was almost identical with that of the control.

The matter of injury to the fruits when deprived of oxygen will be discussed briefly. It may be said that in general there was some injury to the fruits if the nitrogen period extended over 70 hours and when the fruits were pink the injury appeared sooner. The first appearance of injury was that of "oedema-like" watery blisters. In experiments like Io and II in which the nitrogen or hydrogen periods were never over 24 hours there was no apparent injury. The fruits were examined microscopically as well as macroscopically. It was noticed that the protoplasm of the epidermal cells had contracted. The internal cells were all normal in appearance. The fruits were kept on a table in the laboratory for about two months after experiments IO and II, but after this length of time there was nothing in the appearance of the fruits to indicate that they had been deprived of oxygen at any time. Both groups developed an orange-red color. Fruits picked as early as these never developed a red color.

From the fact that the fruits that showed as much respiratory increase as any were not injured there can be no supposition that the $\mathrm{CO}_{2}$ produced is a result of injury, nor does it seem possible that the increased $\mathrm{CO}_{2}$ output could be due to increased permeability of the epidermis to oxygen resulting from the slight injury to the epidermal layer. The increases must be due to causes already discussed. 
From these experiments the conclusion cannot be definitely drawn that tomato fruits do normally, i.e. in air, carry on intramolecular respiration. However, the hypothesis that they do is very attractive. After having been deprived of oxygen they settle down, after some hours, to a very regular and steady rate of respiration which is merely on a lower level than that in air. Otherwise, as illustrated by figures I and 2, fruits respiring intramolecularly are not different from the controls. In fact their respiratory rate remains more nearly constant than that of the controls. The injury mentioned is mostly to the external cells which are normally supplied with an abundance of oxygen, and not to the cells in the interior where oxygen tension must be low at all times. It seems highly probable that under normal conditions the interior respires to some extent, at least, intramolecularly, and the exterior aërobically. When oxygen is replaced the outer cells have to change their mode of respiration; the product of their respiration is poisonous to the cells and they are injured. The lowering in total respiration for a fruit may be considered as the difference between the intramolecular plus aërobic respiration in air and intramolecular alone in absence of air.

Intramolecular respiration as a normal process of various higher plants has, of course, been long known. Thus Gerber (3) stated in 1896 that there is intramolecular respiration in various fleshy fruits during the ripening processes and that this is connected with the formation of esters associated with these fruits. Devaux (2) has shown that there is a deficiency of oxygen in the interior of stems of trees and as a consequence intramolecular respiration takes place in these parts. He also believes that he has detected alcohol in such stems, under normal conditions.

The experiments here reported support these contentions to some extent, but further examinations of the gases in the interior of fruits and also an examination of the $\mathrm{CO}_{2} / \mathrm{O}_{2}$ ratio when the fruits are in air is necessary before one can definitely state that intramolecular respiration is a normal process in tomato fruits. Even if no alcohol were found intramolecular respiration might still take place, since other substances besides alcohol can be formed in intramolecular respiration.

\section{Summary and Conclusions}

I. When tomato fruits of all ages and stages of development are deprived of oxygen by substituting nitrogen or hydrogen there is usually an increase in $\mathrm{CO}_{2}$ production.

2. This increase is followed within a few hours by a large decrease below the normal rate.

3. After this decrease the rate of $\mathrm{CO}_{2}$ production drops only very gradually (no more than in the control) during an experiment lasting for several days.

4. Light yellow or pink fruits form an exception to this rule. Their $\mathrm{CO}_{2}$ production drops very rapidly from the first short increase. 
5. When air is again introduced there is always an increase in $\mathrm{CO}_{2}$ production. In some fruits this increase is very large, in others small.

6. In a given fruit the amount and continuance of this increase is dependent upon the length of the period of intramolecular respiration.

7. This being so it is suggested that during the intramolecular phase of respiration substances are formed which, when air is again admitted, are rapidly oxidized to $\mathrm{CO}_{2}$ and water.

8. The production of $\mathrm{CO}_{2}$ in the absence of oxygen is not due to injury to the fruits, as the fruits in many experiments were in perfect condition at the end.

Department of Botany, University of Michigan

\section{LITERATURE CITED}

I. Blackman, F. F. Analytic studies in plant respiration III. Formulation of a catalytic system for respiration of apples and its relation to oxygen. Proc. Roy. Soc. London B, I03: 49I-523. I928.

2. Devaux, H. Asphyxie spontanée et production d'alcohol dans les tissus profonds des tiges ligneuses poussant dans les conditions naturelles. Compt. Rend. Acad. Sci. Paris 128: $1346-1350$. I 899 .

3. Gerber, C. Recherches sur la maturation des fruits charnus. Ann. Sci. Nat. Bot. VIII, 4: I-279. I 896 .

4. Gustafson, F. G. Growth studies on fruits. Respiration of tomato fruits. Plant Physiol. 4: 349-356. 1929 .

5. Hover, J. M., and F. G. Gustafson. Rate of respiration as related to age. Jour. Gen. Physiol. 10: 33-39. 1926.

6. International Critical Tables 5: 64. New York, 1929.

7. Meyerhof, 0 . Über den Zusammenhang der Spaltungsvorgänge mit der Atmung in der Zelle. Ber. Deutsch Chem. Ges. 58: 99I-IO0I, I 925. 